\title{
Blood Transfusions in Laparoscopic Living Donor Nephrectomy: Single Center Experience from 500
} Cases

\section{Senohadi Boentoro (D) \\ Irfan Wahyudi \\ Chaidir A Mochtar \\ Agus Rizal AH Hamid}

Department of Urology, Faculty of Medicine, Universitas Indonesia, Cipto Mangunkusumo Hospital, Jakarta, Indonesia
This article was published in the following Dove Press journal: Research and Reports in Urology

Introduction: Laparoscopic surgery has been acknowledged to reduce the morbidity rate thus improving patient safety. During the LLDN, the most frequent complication is renal vessels injuries, which often requires a blood transfusion. Besides the need for a blood transfusion, major bleeding caused by renal vessels injuries requires open conversion and repair. Thus, this study would like to descript and analyze the need for blood transfusion in laparoscopic living donor nephrectomy surgery in our center.

Methods: We performed a retrospective cohort study in the Department of Urology at Cipto Mangunkusumo National Hospital. The records of all kidney transplantation donor patients who underwent LLDN procedures carried out at our institution from November 2011 to October 2017 were reviewed. Data including donor age, preoperative hemoglobin level, postoperative hemoglobin level, intraoperative bleeding, number of artery(ies), number of vein(s), donor side, conversion to open surgery, surgery duration, and donor BMI were collected and analyzed. These data were further correlated with the transfusion rate.

Results: There were 500 patients underwent laparoscopic living donor nephrectomy procedure at our institution. All of the patients had LLDN with a transperitoneal approach. The difference in blood transfusion rate proportion between male patients with $0.9 \%$ compared to $0.6 \%$ in female patients was not significant $(p=0.782)$. There is no significant difference in blood transfusion rate proportion regarding renal side $(p=0.494)$, number of artery $(p=0.362)$, age $(p=0.978)$, BMI $(p=0.569)$, and preoperative hemoglobin $(p=0.766)$. Median estimated blood loss in patients who received intraoperative blood transfusion was significantly much greater than in patients who did not receive a blood transfusion $(p<0.001)$.

Conclusion: Based on this study, we suggest that in our institution, preoperative blood products are not necessarily needed. The surgeon's learning curve and technique play a significant role in preventing intraoperative complications and blood loss.

Keywords: transfusion rate, laparoscopic living donor nephrectomy, renal transplantation

\section{Background}

Kidney transplantation is considered the ideal management for patients with endstage renal disease (ESRD). Compared with other renal replacement therapy, such as dialysis, kidney transplantation offers an improved quality of life, reduced mortality, and much lower cost. ${ }^{1,2}$ As the number of people in need of a transplant continues to rise globally, there are limited deceased donors to meet the demand. ${ }^{3,4}$ Donation of a kidney from a living donor is the most realistic option to expand the donation. From 1998 to 2007, living donor organ transplantation
Correspondence: Irfan Wahyudi Email irf.wahyudi20II@gmail.com 
surged by $37 \%$ and the largest increase of living donors has come from unrelated living donors. A kidney from a living donor offers many advantages including a longer duration of patient and graft survival, shorter wait times to receive a kidney, and substantial health care savings from averted years on dialysis. ${ }^{5}$

Since living donor nephrectomy is performed in healthy individuals, the procedure must be as safe and comfortable as possible. The development of a minimally invasive technique has been introduced for living donor nephrectomy surgery. Open donor nephrectomy, as the traditional surgical technique, has known to cause morbidities due to its procedure. Minimal invasive surgery, ie, laparoscopic surgery has been acknowledged to reduce the morbidity rate thus improving patient safety. It also shows other advantages such as less bleeding, faster recovery, less postoperative pain, and better cosmetic results. ${ }^{6,7}$ First laparoscopic living donor nephrectomy (LLDN) was performed by Lloyd Ratner and Louis Kavoussi in $1995 .{ }^{8}$ Since then, the technique of LLDN has undergone evolution at different transplant centers and many modifications have been done to improve donor safety and recipient outcome.

During the LLDN, the most frequent complication is renal vessels injuries, which often requires a blood transfusion. Besides the need for a blood transfusion, major bleeding caused by renal vessel injuries requires open conversion and repair. In Indonesia, kidney transplantation has been done since 1977 and that procedure is increasing and almost outweighs organ availability. The decision to transfuse intraoperatively and early postoperatively is determined by the team managing the patient and involves many factors that cannot always be quantified and may vary based on clinical judgment and patient hemodynamic status shifting on a moment-to-moment basis intraoperatively. Thus, this study would like to describe and analyze the need for blood transfusion in laparoscopic living donor nephrectomy surgery in our center.

\section{Materials and Methods}

We performed a retrospective cohort study in the Department of Urology at Cipto Mangunkusumo National Hospital. Between November 2011 and October 2017, 500 patients underwent laparoscopic living donor nephrectomy procedure at our institution. All of the patients had LLDN with the transperitoneal approach. Three or four trochars were used during the surgery with the pressure of $\mathrm{CO}_{2}$ insufflation maintained along 10-12 $\mathrm{mmHg}$. Retrieval of the kidney donor was performed via suprapubic access created from a Pfannenstiel incision. Since we aimed to analyze the characteristics of patients and the need for intra or postoperative transfusions in these patients, there were no patients excluded from this study. The early LLDN procedures were done by our senior laparoscopic urologist (C. A. H) which had adequate laparoscopic radical nephrectomy experiences. After producing the protocol and standard of the operating procedure, the other three laparoscopic urologists assisted the surgery and then became operator by mentoring system.

Data including donor age, preoperative hemoglobin level, postoperative hemoglobin level, intraoperative bleeding, number of artery, number of vein, donor side, conversion to open surgery, surgery duration, and donor BMI were collected and analyzed. These data were further correlated with the transfusion rate. Numbers of artery were categorized as single artery and multiple arteries. Donor age, hemoglobin level, intraoperative bleeding, donor BMI were analyzed as numeric data. The predictors of transfusion were analyzed. The baseline characteristics of patients who underwent LLDN in our institution are summarized in Table 1.

All variables were characterized using descriptive statistics. Mann-Whitney $U$-test was used to analyze differences in numerical data. A chi-squared test or Fisher test was used for categorical data analysis. A P value of $<0.05$ was considered statistically significant. Statistical analysis was performed using IBM SPSS Statistics (IBM Corp.) version 20 .

Table I Baseline Characteristics of Kidney Transplantation Donor Between November $201 \mathrm{I}$ and October 2017

\begin{tabular}{|l|l|}
\hline Parameters & $\mathbf{n = 5 0 0}$ \\
\hline Age, median (range) & $30(17-62)$ years old \\
Sex, Male: Female Ratio & $343: 157$ \\
BMI, median (range) & $22.90(15.60-39.50) \mathrm{kg} / \mathrm{cm}^{2}$ \\
Number of Artery(ies), Single: Multiple & $447: 53$ \\
Renal Side, Left: Right & $448: 52$ \\
Estimated Blood Loss (median) & $100(15-2000) \mathrm{cc}$ \\
Preoperative Hb & $14.45(8.40-19.40) \mathrm{g} / \mathrm{dl}$ \\
Postoperative Hb & $13.95(8.00-19.10) \mathrm{g} / \mathrm{dl}$ \\
Warm Ischemic Time I & $2.36(1.08-30.43) \mathrm{mins}$ \\
Warm Ischemic Time II & $37.68(12.43-80.20) \mathrm{mins}$ \\
Cold Ischemic Time & $29.52(2.32-92.40) \mathrm{mins}$ \\
Time to Urinate & $2.25(0.13-55.00) \mathrm{mins}$ \\
Surgery Duration & $255(105-425) \mathrm{mins}$ \\
Blood Transfusion Rate & $4(0.8 \%)$ \\
Conversion to Open Surgery & $\mathrm{I}(0.2 \%)$ \\
\hline
\end{tabular}


All data taken for this study have been ethically approved by the Ethics Committee (EC)/Institutional Review Board (IRB) of the University of Indonesia following ICH-GCP standards and requirements. Consent from the patient is not required due to the nature of the retrospective study, where only data from the medical record were taken, and no intervention was performed to the patient. Data from medical records were gathered by two researchers overlooking patient identity, ensuring patient confidentiality in compliance with the Declaration of Helsinki.

\section{Results}

Initial baseline comparison was done and we found that the difference in blood transfusion rate proportion between male patients with $0.9 \%$ compared to $0.6 \%$ in female patients was not significant $(p=0.782)$. Correspondingly, there is no significant difference in blood transfusion rate proportion regarding renal side $(p=0.494)$, number of artery $(p=0.362)$, age $(p=0.978)$, BMI $(p=0.569)$, and preoperative hemoglobin $(p=0.766)$. Median estimated blood loss in patients who received intraoperative blood transfusion was significantly much greater than in patients who did not receive blood transfusion $(p<0.001)$. The bivariate analysis is described in Table 2 .

There were four cases of LLDN that needed blood transfusion. Each of these patients had a blood loss of more than $500 \mathrm{~mL}$ intraoperatively (Table 3 ). One patient was converted to open surgery due to the failure of the

Table 2 Bivariate Analysis of Blood Transfusion Rate

\begin{tabular}{|l|l|l|l|}
\hline \multirow{2}{*}{} & \multicolumn{2}{|l|}{ Blood Transfusion } & \multirow{2}{*}{ P value } \\
\cline { 2 - 3 } & \multicolumn{1}{l|}{ Yes } & No & \\
\hline $\begin{array}{l}\text { Sex } \\
\text { Male }\end{array}$ & $3(0.9 \%)$ & $340(99.1 \%)$ & \multirow{2}{*}{$0.782^{*}$} \\
\hline $\begin{array}{l}\text { Renal Side } \\
\text { Left }\end{array}$ & $1(0.6 \%)$ & $156(99.4 \%)$ & \\
$\quad$ Right & $4(0.9 \%)$ & $444(99.1 \%)$ & \multirow{2}{*}{$0.494^{*}$} \\
\hline $\begin{array}{l}\text { Number of } \\
\text { Artery(ies) }\end{array}$ & $0(0 \%)$ & $52(100 \%)$ & \\
Single & & & \\
Multiple & $3(0.7 \%)$ & $444(99.3 \%)$ & $0.362^{*}$ \\
Age & $1(1.9 \%)$ & $52(98.1 \%)$ & \\
BMI & $32.50(21-51)$ & $30(17-62)$ & $0.978^{* *}$ \\
Pre-Operative Hb & $23.60(20.70-33.80)$ & $22.90(15.60-39.50)$ & $0.569 * *$ \\
Estimated Blood & $14.55(10.80-15.60)$ & $14.40(8.40-19.40)$ & $0.766^{* *}$ \\
Loss & $1300(800-2000)$ & $100(15-1300)$ & $0.000^{* *}$ \\
\hline
\end{tabular}

Notes: *Fisher's Exact Test; **Mann-Whitney Test vascular clip during the ligation of the renal artery. One patient had a blood loss of $1300 \mathrm{~mL}$ due to adrenal injury after nephrectomy. Unfortunately, the medical record of two other cases were already incinerated due to our hospital's policy; therefore, we cannot identify the cause of bleeding.

From all those four cases, only one case needed open conversion surgery to control the bleeding. As for the other three cases, patients were discharged from the hospital without any further intervention besides postoperative blood transfusion.

\section{Discussion}

From this study, the median age of patient in our center is 30 (17-62) years old, which was younger compared to prior studies such as Kok et al with median age 49 (2077) years old, Cintorino et al with median age 49 (28-74) years old, and Felix et al with median age 52.3 (21.680.0) years old for LLDN group. ${ }^{9-11}$ Nowadays, older living donors may be candidates for kidney donation. Controversy remains, as age-related changes in the kidney may result in a decline in renal function over the years, and the combination of aging and a donor nephrectomy is not properly investigated. Therefore, questions have arisen about the outcome of older living kidney donors and especially the decline in estimated glomerular filtration rate (eGFR) after donation. Older donors may also have an increased risk of perioperative complications. They often have a higher "American Society of Anesthesiologists score" (ASA-score), more comorbidity, a higher incidence of hypertension and a higher BMI, all possibly contributing to a higher risk of perioperative problems. ${ }^{12}$ In a study done by Dols et al, living kidney donation by older donors may be considered safe as morbidity of the operation is limited, glomerular filtration rate does not progressively decline, and graft-survival is acceptable. However, this study concludes to carefully select older donors in living kidney donation programs. ${ }^{13}$

Male donor patients are twice as much as female patients. It contrasts with Cintorino (male: female $=45: 99$ ) and Felix (65.1\% subjects were female). ${ }^{12-15}$ Among spousal donors, wives are 2.1-8.2 times more likely to donate than husbands. ${ }^{12-18}$ The issue of gender imbalance in living organ donation and kidney transplantation is multifactorial.

Median BMI in our center is also lower than in prior studies. However, the highest BMI in our center is higher than that in the Kok and Cintorino. In a prior study by 
Table 3 Characteristics of Cases That Required Blood Transfusion

\begin{tabular}{|c|c|c|c|c|}
\hline & Case I & Case 2 & Case 3 & Case 4 \\
\hline Age (years old) & 27 & 51 & 21 & 38 \\
\hline BMI $(\mathrm{kg} / \mathrm{m} 2)$ & 21.10 & 33.80 & 20.70 & 26.10 \\
\hline Sex & Female & Male & Male & Male \\
\hline Blood Loss (mL) & 1300 & 800 & 2000 & 1300 \\
\hline Transfusions (mL) & 522 & 231 & 652 & 214 \\
\hline Preoperative $\mathrm{Hb}(\mathrm{g} / \mathrm{dL})$ & 10.80 & 14.60 & 14.50 & 15.60 \\
\hline Postoperative Hb (g/dL) & 9.10 & 11.90 & 9.80 & 12.20 \\
\hline Number of Artery(ies) & Single & Single & Multiple & Single \\
\hline Renal Side & Left & Left & Left & Left \\
\hline Surgery Duration (minutes) & 250 & 345 & 420 & 240 \\
\hline Year of Operation & 2012 & 2013 & 2013 & 2017 \\
\hline $\begin{array}{l}\text { Cause of Hemorrhage, and } \\
\text { management }\end{array}$ & $\begin{array}{l}\text { Unknown, post operative finding } \\
\text { (decrease in } \mathrm{Hb} \text { level) } \rightarrow \\
\text { conservative management }\end{array}$ & $\begin{array}{l}\text { Unknown, post operative finding } \\
\text { (decrease in } \mathrm{Hb} \text { level) } \rightarrow \\
\text { conservative management }\end{array}$ & $\begin{array}{l}\text { Failed vascular } \\
\text { clip, conversion } \\
\text { to open surgery }\end{array}$ & $\begin{array}{l}\text { Adrenal injury, } \\
\text { conservative } \\
\text { management }\end{array}$ \\
\hline
\end{tabular}

Øien, et al, female donors' kidneys had a higher incidence of acute rejection episodes than male donors' kidneys (49.8\% vs $38.1 \% ; \mathrm{P}=0.002$ ). However, after interaction analysis was performed to evaluate whether there was an increased risk of graft loss due to a biological interaction between donor age and sex, the study found that the RR of graft loss in recipients of male donors less than 50 years was 2.03 ; $95 \%$ CI 0.91 to 4.60 , in female donors more than 50 years $\mathrm{RR}=2.73$; $95 \%$ CI 1.29 to 5.92 and in male donors more than 50 years $\mathrm{RR}=4.02(1.86-8.96)$. So, this study concludes that no interaction between donor sex and age was found. ${ }^{14}$

Most of our patients had single artery and underwent donor nephrectomy of the left kidney, similar to other studies. $^{9-11}$ The left kidney had many intraoperative advantages due to the optimum vein length for the transplant surgeon. Nevertheless, right LLDN is feasible although it is technically more challenging. In a metaanalysis by Wang et al, right kidney donors had shorter operative time and lower operative blood loss than the left kidney donor. But there were no differences between both sides in donor blood transfusion. ${ }^{12}$ Although the median blood loss in our study is similar to the LLDN group in Kok et al, the highest estimated blood loss in our studies is higher than any other studies. The current literature describes a transfusion rate between $0 \%$ and $3.75 \%$ and a conversion rate between $0 \%$ and $8.3 \%{ }^{19,20}$ It was almost similar to our study where the transfusion rate is $0.8 \%$, but the conversion rate is $0.2 \%$.

Despite the relatively low incidence of bleeding following kidney transplantation, it remains one of the most serious complications. In recent years, much evidence has accumulated to suggest that allogeneic perioperative blood transfusion may increase the risk of infectious complications and reduce long-term survival after surgical procedures. These potentially deleterious effects of allogeneic perioperative blood transfusion demonstrate the need for alternative strategies to manage blood replacement during urologic and non-urologic surgeries, and for more controlled transfusion thre sholds.

From the results shown above, there are no associations between blood transfusion and $\operatorname{sex}(p=0.782)$, renal side $(\mathrm{p}=0.494)$, number of artery $(\mathrm{p}=0.362)$, age $(\mathrm{p}=0.978)$, BMI $(p=0.569)$, and preoperative Hb level $(p=0.766)$. Only estimated blood loss shows a significant association with blood transfusion $(\mathrm{p}<0.001)$. There are no available literature discusses factors associated with blood transfusion requirement in LLDN, but our results are in contrast to prior study where age and low preoperative $\mathrm{Hb}$ level are independent preoperative risk factors for perioperative blood transfusion in partial nephrectomy for renal mass.

Furthermore, as our data had shown, most cases that required blood transfusions were from early LLDN practice in our institution. Therefore, we suggest that the surgeon's learning curve in LLDN also plays a significant role in reducing blood loss.

There are some important limitations to this study. Data were collected from transplantations performed over many years to accrue enough patients; transfusion practices, as well as minor aspects of surgical technique, may have changed during the observed time span. 


\section{Conclusion}

Based on this study, we suggest that in our institution, preoperative blood products are not necessarily needed. Should it be needed intraoperative, emergency blood products could be acquired easily, or transfusion could be done postoperatively, based on operative findings and blood loss. We do not find any particular preoperative characteristics that could predict a high risk of intraoperative bleeding or the need for transfusion.

Furthermore, we suggest that the surgeon's learning curve and technique such as instrument handling, and experience over the years play a significant role in preventing intraoperative complications and blood loss, thus preventing the need for transfusion during or after the procedure.

\section{Disclosure}

The authors report no conflicts of interest in this work.

\section{References}

1. Tonelli M, Wiebe N, Knoll G, et al. Systematic review: kidney transplantation compared with dialysis in clinically relevant outcomes. $\mathrm{Am}$ $J$ Transplant. 2011;11(10):2093-2109. doi:10.1111/ajt.2011.11.issue-10

2. Yoo KD, Kim CT, Kim MH, et al. Superior outcomes of kidney transplantation compared with dialysis: an optimal matched analysis of a national population-based cohort study between 2005 and 2008 in Korea. Medicine (Baltimore). 2016;95(33):e4352. doi:10.1097/MD.00 00000000004352

3. Moore DR, Serur D, Rudow DL, Rodrigue JR, Hays R, Cooper M. Living donor kidney transplantation: improving efficiencies in live kidney donor evaluation recommendations from a consensus conference. Clin J Am Soc Nephrol. 2015;10:1678-1686. doi:10.22 15/CJN.01040115

4. Kim SJ, Fenton SS, Kappel J, et al. Organ donation and transplantation in Canada: insights from the Canadian Organ Replacement Register. Can J Kidney Health Dis. 2014;1:31. doi:10.1186/s40697-014-0031-8

5. Cecka JM. Living donor transplants. In: Cecka JM, Terasaki PI, editors. Clinical Transplants 1995. Los Angeles, CA: UCLA Tissue Typing Laboratory; 1996:363-367.

6. Simforoosh N, Basiri A, Tabibi A, Shakhssalim N, Hosseini Moghaddam SM. Comparison of laparoscopic and open donor nephrectomy: a randomized controlled trial. BJU Int. 2005;95:851-855. doi:10.1 111/j.1464-410X.2005.05415.x
7. Nanidis TG, Antcliffe D, Kokkinos C, et al. Laparoscopic versus open live donor nephrectomy in renal transplantation: a meta-analysis. Ann Surg. 2008;247:58-70. doi:10.1097/ SLA.0b013e318153fd13

8. Ratner LE, Ciseck LJ, Moore LG, et al. Laparoscopic live donor nephrectomy. Transplantation. 1995;60:1047-1049.

9. Kok NFM, Lind MY, Hansson BME, et al. Comparison of laparoscopic and mini incision open donor nephrectomy: single blind, randomised controlled clinical trial. BMJ. 2006;333(7561):221. doi:10.1136/bmj.38886.618947.7C

10. Cintorino D, Pagano D, Bonsignore P. et al. Evolution of technique in laparoscopic donor nephrectomy: a single center experience. J Laparoendosc Adv Surg Tech A. 2017;27(7):666-668. doi:10. 1089/lap.2017.0140

11. Burkhalter F, Huynh-Do U, Hadaya K. et al. Early complications after living donor nephrectomy: analysis of the Swiss organ living donor health registry. Swiss Med Wkly. 2017;147:w14497.

12. Kayler LK, Meier-Kriesche HU, Punch JD, et al. Gender imbalance in living donor renal transplantation. Transplantation. 2002; 73:248-252. doi:10.1097/00007890-200201270-00017

13. Kayler LK, Armenti VT, Dafoe DC, et al. Patterns of volunteerism, testing, and exclusion among potential living kidney donors. Health Care Women Int. 2005;26:285-294. doi:10.1080/07399330590925 772

14. Zimmerman D, Donnelly S, Miller J, et al. Gender disparity in living renal transplant donation. Am J Kidney Dis. 2000;36:534-540. doi:10.1053/ajkd.2000.9794

15. Bloembergen WE, Port FK, Mauger EA, et al. Gender discrepancies in living related renal transplant donors and recipients. $J$ Am Soc Nephrol. 1996;7:1139-1144.

16. Kayler LK, Rasmussen CS, Dykstra DM, et al. Gender imbalance and outcomes in living donor renal transplantation in the United States. Am J Transplant. 2003;3:452-458. doi:10.1034/j.1600-6143.2003.00 086.x

17. Khajehdehi P. Living non-related versus related renal transplantationits relationship to the social status, age and gender of recipients and donors. Nephrol Dial Transplant. 1999;14:2621-2624. doi:10.1093/ $\mathrm{ndt} / 14.11 .2621$

18. Port FK, Merion RM, Finley MP, et al. Trends in organ donation and transplantation in the United States, 1996-2005. Am J Transplant. 2007;7:1319-1326. doi:10.1111/ajt.2007.7.issue-s1

19. Percegona LS, Bignelli AT, Adamy A Jr, et al. Early graft function in kidney transplantation: comparison between laparoscopic donor nephrectomy and open donor nephrectomy. Transplant Proc. 2008;40:685-686. doi:10.1016/j.transproceed.2008.03.006

20. Choi SW, Kim KS, Kim S, et al. Hand-assisted and pure laparoscopic living donor nephrectomy: a matched-cohort comparison over $10 \mathrm{yr}$ at a single institute. Clin Transplant. 2014;28:1287-1293. doi:10. 1111/ctr.2014.28.issue-11

\section{Publish your work in this journal}

Research and Reports in Urology is an international, peer-reviewed, open access journal publishing original research, reports, editorials, reviews and commentaries on all aspects of adult and pediatric urology in the clinic and laboratory including the following topics: Pathology, pathophysiology of urological disease; Investigation and treatment of urological disease; Pharmacology of drugs used for the treatment of urological disease. The manuscript management system is completely online and includes a very quick and fair peer-review system, which is all easy to use. Visit http://www.dovepress.com/ testimonials.php to read real quotes from published authors. 